\title{
Investigation on hydraulic properties of compacted GMZ bentonite used as buffer/backfill material
}

\author{
W. M. Ye ${ }^{1,2, a}$, Q. Xin ${ }^{1}$, B. Chen ${ }^{1}$, Y.G. Chen ${ }^{1}$, Y. J. Cui ${ }^{3}$ \\ ${ }^{1}$ Key Laboratory of Geotechnical and Underground Engineering of Ministry of Education, Tongji University, Shanghai 200092, China \\ ${ }^{2}$ United Research Center for Urban Environment and Sustainable Development, the Ministry of Education, Shanghai 200092, China \\ ${ }^{3}$ Ecole des Ponts ParisTech, UR Navier/CERMES, 77455, France
}

\begin{abstract}
During the past decades, GMZ bentonite has been widely investigated for its use as buffer/backfill materials in China. Based on a comprehensive review of the former studies, achievements on experimental and theoretic works on the hydraulic aspects of compacted GMZ bentonite with consideration of temperature effects are presented in this paper. Water retention property of compacted GMZ bentonite depends on constraint conditions. Temperature effects on water-retention depend on constraint conditions and suction. The hysteresis behaviour is not obvious. Based on the test results, a revised water retention model was developed for considering the temperature effect. The saturated hydraulic conductivity of the densely compacted GMZ bentonite increases as dry density and temperature increases. A revised model, which considers temperature influence on water viscosity and the effective flow cross-sectional area of porous channels, for prediction of saturated hydraulic conductivity have been developed and verified. The unsaturated hydraulic conductivity of confined densely compacted GMZ bentonite samples decreases first and then increases with suction decrease from an initial value of $80 \mathrm{MPa}$ to zero. With consideration of temperature effects and microstructure changes, a revised model for prediction of unsaturated hydraulic conductivity of compacted GMZ01 bentonite was proposed.
\end{abstract}

\section{Introduction}

Bentonite has generally been chosen as buffer and backfill material for construction of engineered barrier in deep geological repository because of its high swelling capacity, low permeability, micro-porous structure and good sorption properties. This clay-based engineering barrier has multiple purposes of providing mechanical stability for the waste canister (by absorbing stresses and deformations); serving as a buffer around it; sealing discontinuities in the emplacement boreholes and drifts; and delaying the water infiltration from the host rock. During the long-term operation of the repository, the engineered clay barrier and adjacent host rock will be subjected to the heating effect of the nuclear waste, to various associated hydraulic and mechanical phenomena that interact in a complex way. Therefore, the hydraulic property of the compacted bentonite is one of the key properties for the design of such a disposal system (Dixon et al., 1987; Nachabe, 1995; Liu and Wen, 2003; Ye et al., 2013; 2014a,b; Villar, 2000; 2002; Komine, 2004). Furthermore, compacted bentonite is initially unsaturated, and will therefore be subjected to hydration from the surrounding rock, triggering further coupled thermo-hydro-mechanical (THM) phenomena.

Chinese high-level radioactive waste repository program was launched in the middle of 1980s (Wang et al., 2006). It was suggested that a high-level radioactive waste repository will be built in the middle of the 21 st Century. Beishan in Gangsu Province has been selected as the potential site for construction of the first repository in China. Gaomiaozi (GMZ) bentonite has been considered as a possible material for the construction of engineered barrier in the recent Chinese program of radioactive waste disposal (Liu et al., 2001; Ye et al. 2009a).

In the past decades, investigations on mineralogy and chemical composition, mechanical properties, hydraulic behavior, swelling behavior, thermal conductivity, microstructure and volume change behavior were performed on GMZ bentonite (Liu and Wen, 2003; Wang et al., 2006; Wen, 2006; Chen et al., 2006; Niu, 2008; Ye et al., 2009a,b; 2010; 2012; Sun et al., 2015). Related results have been reported.

In this paper, based on a comprehensive review of the former studies, the achievements on experimental and theoretic works on hydraulic properties of GMZ bentonite are presented.

\section{Basic properties of GMZ bentonite}

Gaomiaozi (GMZ) bentonite originates from Inner Mongolia, China, $300 \mathrm{~km}$ northwest from Beijing. There are 160 million tons bentonite (with 120 million tons Na-

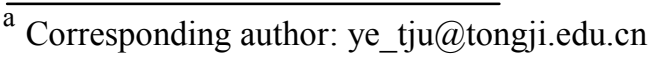


Bentonite) reserves in the deposit, which occupies a mining area about $72 \mathrm{~km}^{2}$. The deposit was formed in the later Jurassic period (Liu et al., 2001). GMZ Bentonite is bedded, with a soapy texture and waxy appearance.

The Cation Exchange Capacity (CEC) of GMZ bentonite is showed in Table1 (Ye et al., 2010).

Table 1. Cation exchange capacity of some bentonites (Ye et al., 2010)

\begin{tabular}{cccccc}
\hline \multirow{2}{*}{ Sample } & \multirow{2}{*}{$\begin{array}{c}\mathrm{CEC} \\
(\mathrm{meq} / 100 \mathrm{~g})\end{array}$} & \multicolumn{4}{c}{ Exchangeable cation (meq/100 g) } \\
\cline { 3 - 6 } & & $\mathrm{E}(\mathrm{K}+)$ & $\mathrm{E}\left(\mathrm{Na}^{+}\right)$ & $\mathrm{E}\left(1 / 2 \mathrm{Ca}^{2+}\right)$ & $\mathrm{E}\left(1 / 2 \mathrm{Mg}^{2+}\right)$ \\
\hline $\mathrm{GMZ}$ & 77.30 & 2.51 & 43.36 & 29.14 & 12.33 \\
\hline
\end{tabular}

Some basic physical properties of GMZ bentonite are presented in Table 2 .

Table 2. Physical properties of GMZ01 bentonite (Ye et al., 2014)

\begin{tabular}{cc}
\hline Property & Description \\
\hline Specific gravity of soil grain & 2.66 \\
$\mathrm{pH}$ & $8.68-9.86$ \\
Liquid limit (\%) & 276 \\
Plastic limit (\%) & 37 \\
Total specific surface area/ & 570 \\
$\left(\mathrm{~m}^{2} \cdot \mathrm{g}^{-1}\right)$ & \\
\hline Main minerals & Montmorillonite $(75.4 \%)$, \\
& quartz $(11.7 \%)$, \\
feldspar $(4.3 \%)$, \\
cristobalite $(7.3 \%)$
\end{tabular}

Results in Tab. 1 and Tab. 2 show that GMZ bentonite has high montmorillonite content, which gives it a high Cations Exchange Capacity (CEC $=77.30$ meq/100g), a large plasticity index $(\mathrm{Ip}=239)$, and a large specific surface area $\left(\mathrm{S}=570 \mathrm{~m}^{2} / \mathrm{g}\right)$.

\section{Water retention properties}

Using the vapour phase technique and the osmotic technique, the WRCs of both the confined and unconfined GMZ bentonite specimens were measured at room temperature $\left(20^{\circ} \mathrm{C}\right)$ by Chen et al. (2006) (Fig. 1). The result in Fig. 1 shows that, starting from the initial suction of $4.2 \mathrm{MPa}$, the difference between different confining conditions becomes less significant as the suction increases. However, for suctions lower than 4 $\mathrm{MPa}$, the confined specimen gives much lower water content: at the lowest suction $(0.013 \mathrm{MPa})$ measured the difference in water content is as large as $140 \%$.

The water retention curves obtained under temperatures following the wetting path for the unconfined GMZ01 bentonite specimens with a dry density of $1.70 \mathrm{~g} / \mathrm{cm}^{3}$ are presented in Fig. 2. It is observed that temperature effect on the water retention capacity is insignificant.

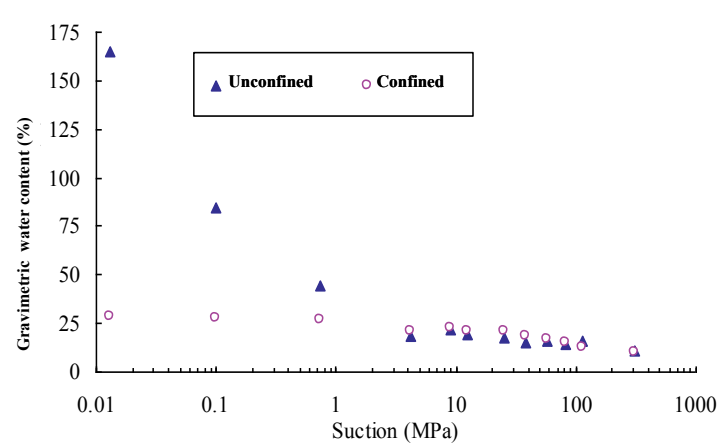

Fig. 1. WRCs of the GMZ bentonite with dry density of 1.7 $\mathrm{g} / \mathrm{cm}^{3}$ under confined and unconfined conditions at room temperature (Chen et al., 2006)

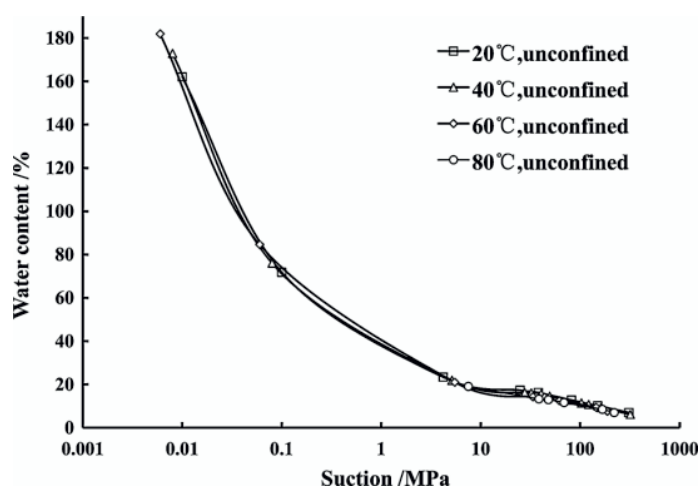

Fig. 2 SWRCs of compacted GMZ bentonite under unconfined conditions $\left(20,40,60\right.$ and $80^{\circ} \mathrm{C}$ ) (Wan et al., 2015)

For measuring the SWRCs at temperatures, salt solutions and their corresponding suctions at temperatures in Table 2 (Tang and Cui, 2005) were employed. The temperature effect on the suction imposed by PEG solutions is $1 \% /{ }^{\circ} \mathrm{C}$ (Tang et al., 2010) was accepted for application of osmotic technique.

The water retention curves of confined compacted GMZ bentonite following wetting path at different temperatures are presented in Fig. 3.

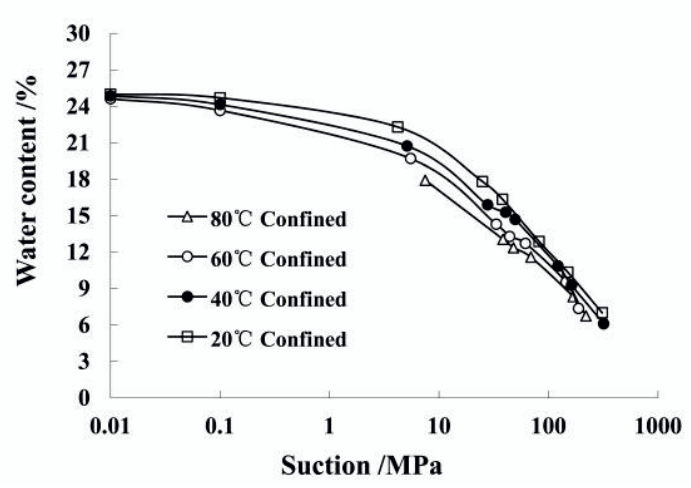

Fig. 3. SWRCs of compacted GMZ bentonite under confined conditions $\left(20,40,60\right.$ and $80^{\circ} \mathrm{C}$ ) (Wan et al., 2015)

Curves in Fig. 3 show that, for confined specimens, the water retention capacity decreases as temperature rises. Moreover, this temperature influence strongly depends on suction. When the suction is close to zero $(0.01 \mathrm{MPa})$, the temperature effect is hardly observed. A possible explanation of this observation is that the lateral swelling stress applied to the compacted bentonite sample 
increases with suction decrease under confined conditions. Meanwhile, decreasing suction could not make more water moving into large pores, as most of the pores have already been filled with water.

Comparison between the water retention curves shown in Figs. 2 and 3 reveals that temperature effects on water retention capacity strongly depends on the constraint conditions. This conclusion agrees well with the observations reported by Villar and Lloret (2004).

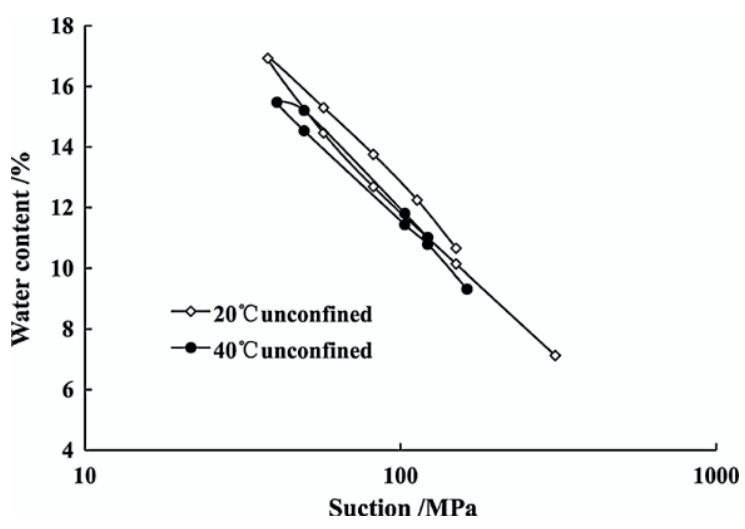

Fig. 4. Hysteresis behavior of unconfined GMZ bentonite at 20 and $40^{\circ} \mathrm{C}$ temperatures (Wan et al., 2015)

The hysteresis curves of unconfined compacted GMZ bentonite following wetting / drying cycles at 20 and 40 ${ }^{\circ} \mathrm{C}$ are shown in Fig. 4. It is observed that the hysteresis behavior becomes less obvious with temperature increase, in agreement with the observation reported by Ye et al. (2009b). This indicates that, as temperature increases, the water retention capacity and the hysteresis decrease regardless of the confining conditions. Fig. 4 also shows that the influence of temperature on the hysteresis behavior depends on the suction level: the higher the temperature, the less obvious the hysteresis behavior.

For modelling the soil water retention behavior of compacted GMZ bentonite with consideration of temperature effects, based on a comprehensive review of literatures (Brooks and Corey 1964; van Genuchten 1980; Fredlund and Xing 1994; Leij et al. 1997; Sánchez, 2004; Jacinto et al., 2009), Wan et al. (2015) established the following equation to describe the water retention curves of the densely compacted GMZ bentonite $\left(1.7 \mathrm{Mg} / \mathrm{m}^{3}\right)$ with consideration of temperature effects:

$$
w=\left(1-\frac{\ln \left(1+\frac{\psi}{\psi_{r}}\right)}{1+\frac{1000}{\psi_{r}}}\right) \frac{w_{s a t}^{0}+\zeta\left(T-T_{0}\right)}{\left\{\ln \left[e+(\psi /(\eta \operatorname{Ln}(T-273)+\varepsilon))^{n}\right]\right\}^{m}}
$$

Where $w_{\text {sat }}^{0}(T)=0.25 ; \quad \zeta=0.00018 ; T_{0}=273.4$. By fitting the SWRC measured at $20^{\circ} \mathrm{C}$ using equation (1), for the confined compacted GMZ01 bentonite with a dry density of $1.7 \mathrm{Mg} / \mathrm{m}^{3}$, parameters $\mathrm{m}$ and $\mathrm{n}$ are determined, equal to 0.5864 and 0.8086 , respectively.

With equation (1), the SWRCs of compacted GMZ01 bentonite at $60^{\circ} \mathrm{C}$ and $80^{\circ} \mathrm{C}$ were calculated and compared to the measured ones. Comparison demonstrates that the revised model can satisfactorily describe the soil water retention properties of the confined compacted GMZ01 bentonite changing with temperature.

\section{Hydraulic conductivity}

\subsection{Saturated hydraulic conductivity}

With self-made apparatus, Ye et al. (2013) measured the saturated hydraulic conductivity of densely $\left(1.70 \mathrm{~g} / \mathrm{cm}^{3}\right)$ compacted GMZ bentonite at temperatures (Fig. 5).

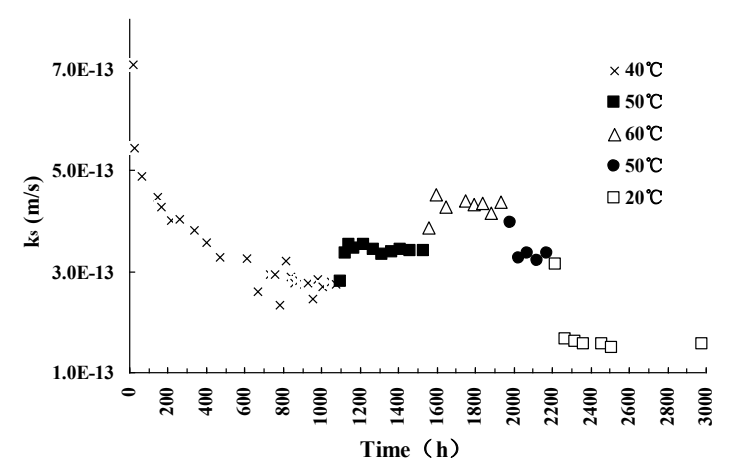

Fig. 5. Evolution of saturated hydraulic conductivity of the compacted GMZ bentonite with time at temperatures (Ye et al., 2013)

According to the test results, the following equation was proposed for prediction of the saturated hydraulic conductivity of the compacted GMZ bentonite considering temperature influences on both water viscosity and effective flow cross area (apparent porosity) in its porous channels (Ye et al., 2013).

$k_{s}=\frac{k_{i n}(T) \rho_{w} g}{\eta(T)}=\frac{\exp (-45.703+0.0054 \times(T-273)) \rho_{w} g}{0.0002601+0.001517 \exp [-0.034688 \times(\mathrm{T}-273)]}$

Where $k_{s}$ is saturated hydraulic conductivity, $k_{\text {in }}$ intrinsic hydraulic conductivity, $\eta$ water viscosity, $T$ is temperature, $\rho_{w}$ is water density and $g$ is acceleration of gravity.

Calculation shows that the proposed model (eq. (2)) can well describe the temperature influences on the saturated hydraulic conductivity of the compacted GMZ bentonite.

It should be noted that the values measured during the first $600 \mathrm{~h}$ in Fig. 5 probably correspond to a period when the sample was still unsaturated.

\subsection{Unsaturated hydraulic conductivity}

Using a self-designed cell, Ye et al. (2009a) measured the unsaturated hydraulic conductivity of GMZ bentonite with a dry density of $1.7 \mathrm{~g} / \mathrm{cm}^{3}$ under confined conditions at ambient temperature. With the instantaneous profile method, the unsaturated hydraulic conductivities measured at different locations along the height of the specimen evolving with suction are presented in Fig. 6 . Results in Fig. 6 indicate that, when suction is reduced from the starting point about $80 \mathrm{MPa}$ to zero, the measured unsaturated hydraulic conductivity firstly decreases from $2 \mathrm{E}-14 \mathrm{~m} / \mathrm{s}$ at $80 \mathrm{MPa}$ suction, then increases from $7 \mathrm{E}-15 \mathrm{~m} / \mathrm{s}$ at $70 \mathrm{MPa}$ suction, and $10 \mathrm{E}-13$ 
$\mathrm{m} / \mathrm{s}$ at zero suction. The decrease can be attributed to the large pore clogging due to the possible exfoliation process (Ye et al., 2009a).

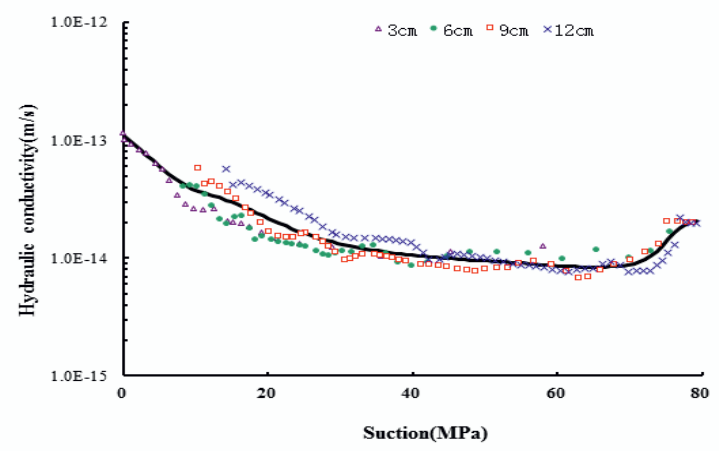

Fig. 6 Evolutions of hydraulic conductivity of the GMZ bentonite at different heights of the specimen with suction under confined conditions (Ye et al., 2009a)

Niu (2008) tested the unsaturated hydraulic conductivity of the densely compacted GMZ bentonite under unconfined conditions at room temperature. Results (Fig. 7) show that the unsaturated hydraulic conductivity is in a larger range of $1.0 \mathrm{E}-12$ and $1.0 \mathrm{E}-15$ $\mathrm{m} / \mathrm{s}$ and it develops gently with suction except for fluctuations both at the initial and the final stages of the experiment.

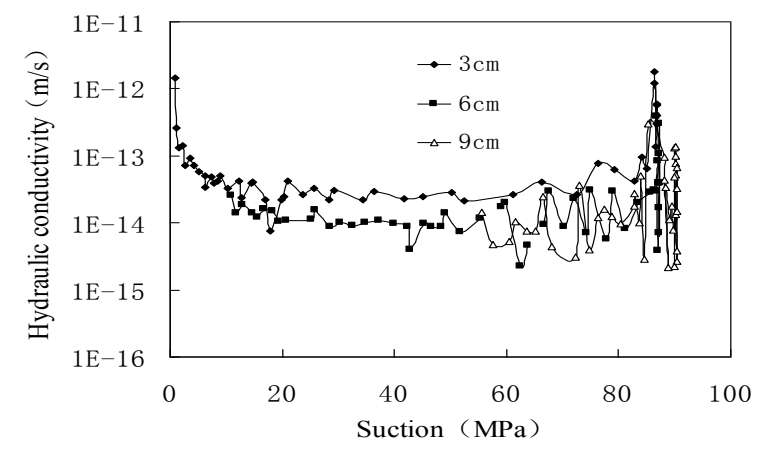

Fig. 7 Evolution of hydraulic conductivity of the GMZ bentonite with suction under unconfined conditions (Niu, 2008)

Comparison of results in Figs. 6 and 7 reveals that, for a same suction, the unsaturated hydraulic conductivity of compacted GMZ bentonite under unconfined conditions is higher than that of under confined conditions. This is possibly induced by the difference in the mechanism of microstructural changes during hydration under different confining conditions.

With self-made apparatus, Ye et al. (2009b; 2012) measured the unsaturated hydraulic conductivity of the confined GMZ specimens at $20^{\circ} \mathrm{C}, 40^{\circ} \mathrm{C}$ and $60^{\circ} \mathrm{C}$, which were compared in Fig. 8. Results show that under confined conditions, the unsaturated hydraulic conductivity of the highly compacted GMZ bentonite increases with temperature rise. This temperature effect can be explained by changes of water viscosity (Duley and Domingo, 1943; Hopmans and Dane, 1986; Constantz and Murphy, 1991), water density, and to some extent the intrinsic hydraulic conductivity (Villar et al., 2005). Among which, the water viscosity has been found to be the most significant factor (Delage et al., 2000).
Moreover, the rate of change also decreases as temperature increases. The temperature effect becomes more significant at higher suctions (above $20 \mathrm{MPa}$ ). In the range of lower suctions (less than $20 \mathrm{MPa}$ ), it is observed that the lower the suction, the less the temperature effect. The possible explanation is that for lower suctions the moisture absorbed by the bentonite is mainly associated with microstructure changes and the temperature effect on the microstructure is not significant.

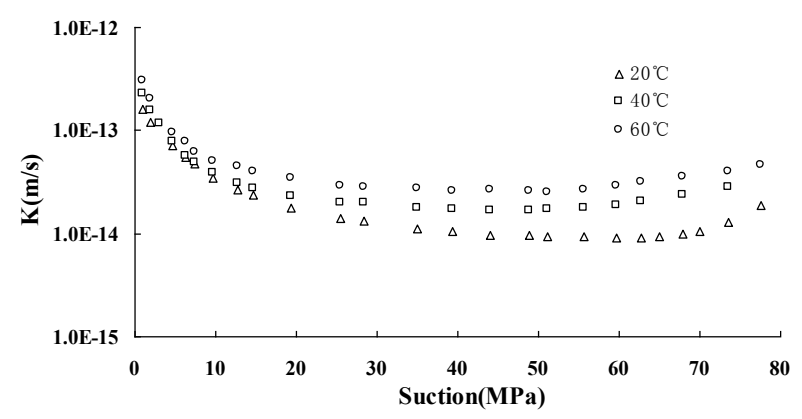

Fig. 8 Evolution of unsaturated hydraulic conductivity with suction for the confined GMZ bentonite at temperatures (Ye et al., 2012)

According to the test results, a revised fractal model for prediction of unsaturated hydraulic conductivity of compacted bentonite with consideration of temperature effects and microstructure changes was developed by Ye et al. (2014b).

$k_{w}=k_{s}(T) k_{r}(s, T)=k_{s}(T) \times A \times B\left(\frac{s(T)}{a(T)}\right)^{-\lambda(n+1+2 / \lambda)}$

Where, $k_{s}(T)$ is saturated hydraulic conductivity of compacted GMZ bentonite with consideration of temperature effects, which can be expressed by equation (2). Parameter $A$ is the influencing factor of microstructure changes, $B$ is the influence coefficient of the effective degree of saturation on the variation of void ratio. For the compacted GMZ01 bentonite specimen tested: $B=0.515$. Based on the measured unsaturated hydraulic conductivity of densely compacted GMZ01 bentonite with a dry density of $1.7 \mathrm{Mg} / \mathrm{m}^{3}$ under confined conditions at temperatures $40^{\circ} \mathrm{C}$ and $60^{\circ} \mathrm{C}$ in Fig. 8, parameters $A$ and $n$ were fitted: $n=-5.371$ and $A=0.51$. With MIP observations, the value of the fractal dimension $D=2.712$ and the fractal dimension coefficient $\lambda=0.288$.

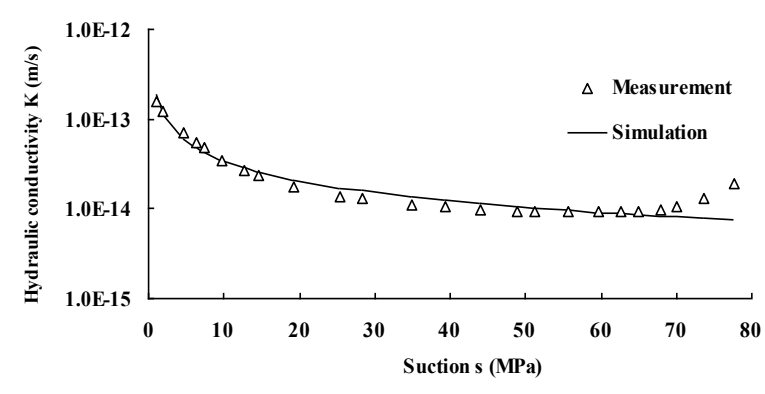

Fig. 9 Comparison between the prediction and measurement at $20^{\circ} \mathrm{C}$ temperature (Ye et al., 2014) 
Verification result (Fig. 9) indicates that equation (3) can give good prediction of the unsaturated hydraulic conductivity of densely compacted GMZ01 bentonite under confined conditions in a suction range of $0-70 \mathrm{MPa}$. However, deviation occurs in higher suctions $(>70 \mathrm{MPa})$. This deviation may result from the inter-aggregate pores clogging (Ye et al., 2009b), which probably induced by possible exfoliation process that occurs around the macro-pores during aggregate hydration (Pusch et al. 2012; Pusch and Yong 2003; Pusch et al. 2010).

\section{Conclusions}

Based on a review of the former studies, achievements on experimental and theoretic results obtained on the hydraulic behaviour of compacted GMZ bentonite are presented in this paper.

The influences of constraint conditions on water retention properties of GMZ bentonite depends on the range of suction. Temperature effects depends on constraint conditions and suction. Under unconfined conditions, the effect of temperature at high suctions is different from that at low suctions. The hysteresis behaviour of unconfined compacted bentonite is not obvious on the whole, even it was found reduced with temperature increase. A revised water retention model was developed for considering the temperature effect. Comparison between the calculated results and the experimental data shows the relevance of the model developed in describing the water retention properties of compacted GMZ bentonite at different temperatures under confined conditions.

The saturated hydraulic conductivity of the GMZ bentonite decreases as dry density increases and increases as temperature increases. With consideration of both the temperature influence on water viscosity and the effective flow cross-sectional area of porous channels, the proposed model can satisfactorily account for the temperature effects.

The unsaturated hydraulic conductivity of GMZ bentonite firstly decreases and then increases with suction decrease from an initial value of $80 \mathrm{MPa}$ to zero. This phenomenon could be attributed to the large pore clogging due to exfoliation process. The unsaturated hydraulic conductivity of compacted GMZ bentonite under unconfined conditions is higher than that under confined conditions. Under confined conditions, the unsaturated hydraulic conductivity of the highly compacted GMZ bentonite increases with temperature rise. Moreover, the changing rate depends on suction.

\section{Acknowledgments}

The authors are grateful to the National Natural Science Foundation of China (Projects No. 41527801, 41272287), the China Atomic Energy Authority (Project [2011]1051) for the financial supports.

\section{References}

1. Brooks, R.H., Corey, A.T., 1964. Hydraulic properties of porous media Colorado State Univ. Hydrol. Paper, no.3.

2. Chen, B., Qian, L.X., Ye, W.M., Cui, Y.J., Wang, J. 2006. Soil-water characteristic curves of Gaomiaozi Bentonite. Chinese Journal of Rock Mechanics and Engineering. 21:10541058 .

3. Constantz, J., Murphy, F. 1991. The temperature dependence of ponded infiltration under isothermal conditions. J Hydrol 122, 119-128.

4. Cui, Y.J., Tang, A.M., Loiseau, C., Delage, P. 2008. Determining the unsaturated hydraulic conductivity of a compacted sand-bentonite mixture under constant-volume and free-swell conditions. Physics and Chemistry of the Earth 33, 462-471.

5. Delage, P., Sultan, N., Cui, Y.J. 2000. On the thermal consolidation of Boom clay. Can Geotech J 37 (2), 343-354.

6. Dixon, D.A., Cheung, S.C.H., Gray, M.N., Davidson, B.C. 1987. The hydraulic conductivity of dense clay soils. Proceedings of the 40th Canadian Geotechnical Conference, Regina, Saskachewan - Canada, pp. 389-396.

7. Duley, F.L., Domingo, C.E. 1943. Effect of wáter temperatura on rate of infiltration. Soil Sci Soc proc 31, 129-131.

8. Fredlund, D.G., Xing, A. 1994. Equations for the soil-water characteristic curve. Canadian Geotechnical Journal, Volume 31, 521-532.

9. Hopmans, J., Dane, J. 1986. Temperature dependence of soil hydraulic properties. Soil Sci Soc Am J 50, 4-9.

10. Jacinto, A.C., Villar, M.V., Gómez-Espinab R., Ledesma A. 2009. Adaptation of van Genuchten expression to the effects of temperature and density for compacted bentonites. Applied Clay Science 42, 575-582.

11. Komine, H. 2004. Simplified evaluation on hydraulic conductivities of sand-bentonite mixture backfill. Applied Clay Science 26 (1-4), 13-19.

12. Leij, F.J., Russell, W.B., Lesch, S.M. 1997. Closed-form expressions for water retention and conductivity data. Ground Water 35, 848-858.

13. Liu, Y.M., Xu, G.Q., Liu, S.F. 2001. Study on the Basic Property of Gaomiaozi Bentonite, Inner Mongolia. China Nuclear Industry Audio and Visual Publishing House, Beijing, 1-20 (in Chinese).

14. Liu, Y.M., Wen, Z.J. 2003. An investigation of the physical properties of clayey materials used in nuclear waste disposal at great depth. Mineral rocks 23 (4), 42-45 (in Chinese).

15. Nachabe, H.M. 1995. Estimating hydraulic conductivity for models of Soils with Macropores. Journal of Irrigation and Drainage Engineering 121 (1), 95-102. 
16. Niu, W.J. 2008. Study on unsaturated permeability of densely compacted bentonite under free swelling conditions. Ph.D-thesis, Tongji University, Shanghai (in Chinese).

17. Pusch R., Prikryl R., Weishauptová Z, Liu X. D. , Knutsson S. 2012. Role of clay microstructure in expandable buffer clay. Journal of Purity, Utility Reaction and Environment Vol.1 No.6, 297-322.

18. Pusch R., Yong R. 2003. Water saturation and retention of hydrophilic clay buffer-micro structural aspects. Applied Clay Sci 23, 61- 68

19. Pusch, R., Yong, R.N., Nakano, M., 2010. Stiffening of smectite buffer clay by hydrothermal effects. Engineering Geology, Vol.116. pp. 21-31

20. Sun, W.J., Wei Z.F., Sun, D.A., Liu, S.Q., Fatahi, B., Wang, X.Q., 2015. Evaluation of the swelling characteristics of bentonite-sand mixtures. Engineering Geology, 199. 1-11.

21. Sánchez, M. 2004. Thermo-hydro-mechanical coupled analysis in low permeability media. The Polytechnic University of Catalunya, Barcelona.

22. Tang A.M.,Cui Y.J. 2005. Controlling suction by the vapour equilibrium technique at different temperatures and its application in determining the water retention properties of MX80 clay. Can. Geotech. J. 42:1-10.

23. Villar, M.V. 2000. Caracterización termo-hydromecánica de una bentonita de Cabo de Gata: Ph.D. Thesis. Universidad Complutense de Madrid. Madrid (in Spanish).

24. Villar, M.V. 2002. Thermo-hydro-mechanical characterization of a bentonite from Cabo de Gata. A study applied to the use of bentonite as sealing material in high level radioactive waste repositories. Publicación Técnica ENRESA, Madrid, Spain.

25. Villar M.V., Lloret A. 2004. Influence of temperature on the hydromechanical behaviour of a compacted bentonite. Appl Clay Sci 26: 337-350

26. Villar, M.V.; Romero, E. \& Lloret, A. 2005. Thermo-mechanical and geochemical effects on the permeability of high-density clays. In: ALONSO, E.E. \& LEDESMA, A. (eds.): Advances in understanding engineered clay barriers. A.A. Balkema Publishers, Leiden. 177191. ISBN 04-1536-544-9.

27. Van Genuchten, M. Th. 1980. A closed-form equation for predicting the hydraulic conductivity of unsaturated soils. Soil Sci. Soc. Am. 44, 892-898.

28. Wan M, Ye WM*, Chen YG, Cui YJ, Wang J. 2015. Influence of temperature on the water retention properties of compacted GMZ01 bentonite. Environmental Earth Sciences. 73(8): 4053-4061.

29. Wang, J., Sui, R., Chen, W., Guo, Y.H., Jin, Y.X., Wen, Z.J., Liu, Y.M. 2006. Deep geological disposal of high-level radioactive wastes in China. Chinese Journal of Rock Mechanics and Engineering, 25 (4), 649-658.

30. Wen, Z.J. 2006. Physical property of China's buffer material for high level radioactive waste repositories. Chinese Journal of Rock Mechanics and Engineering 25, 794-800 (in Chinese).

31. Ye, W.M., Cui, Y.J., Qian, L.X., Chen, B. 2009a. An experimental study of the water transfer through confined compacted GMZ bentonite. Engineering Geology, Volume 108, 169-176.

32. Ye, W.M., Wan, M., Chen, B., Chen, Y.G., Cui, Y.J., Wang, J. 2009b. Effect of temperature on soil-water characteristics and hysteresis of compacted Gaomiaozi bentonite. J of Central South Univ of Tech 16 (5), 821-826.

33. Ye, W.M., Chen, Y.G., Chen, B., Wang, Q., Wang, J. 2010. Advances on the knowledge of the buffer/backfill properties of heavilycompacted GMZ bentonite. Engineering Geology, Volume 116, Issues 1-2, Pages 12-20.

34. Ye, W.M., Wan, M., Chen, B., Chen, Y.G., Cui, Y.J., Wang, J. 2012. Temperature effects on the unsaturated permeability of the densely compacted GMZ01 bentonite under confined conditions. Engineering Geology, Vol 126, 1-7

35. Ye, W.M., Wan, M., Chen, B., Chen, Y.G., Cui, Y.J. 2013. Temperature effects on the swelling pressure and saturated hydraulic conductivity of the compacted GMZ01 bentonite. Environmental Earth Science, Vol 68, 281-288.

36. Ye WM, N.C. Borrell, J.Y. Zhu, B. Chen, Y.G. Chen. 2014a. Advances on the investigation of the hydraulic behaviour of compacted GMZ bentonite. Engineering Geology 169: 41-49

37. Ye, W.M., Wan, M., Chen, B., Chen, Y.G., Cui, Y.J., Wang, J. 2014b. An Unsaturated Hydraulic Conductivity Model for Compacted GMZ01 Bentonite with Consideration of Temperature. Environmental Earth Sciences. 71(4): 1937-1944 